\title{
CD38 negative anaplastic plasma cell myeloma with $(14 ; 16)$ translocation: a diagnostic dilemma for highly aggressive neoplasm: case report
}

\author{
Mansour S. Aljabry ${ }^{1}$
}

Received: 10 October 2018 / Accepted: 18 December 2018 / Published online: 2 January 2019

(C) Springer-Verlag GmbH Germany, part of Springer Nature 2019

\begin{abstract}
Anaplastic plasma cell myeloma (PCM) is an aggressive morphological variant of myeloma characterized by involvement of extramedullary sites and extremely poor prognosis. Moreover, anaplastic PCM is frequently associated with high frequency of $17 \mathrm{p}(\mathrm{p} 53)$ deletions, 1q21(CKS1B) amplifications and immunoglobulin A (IgA) isotype. It usually manifests as an adverse progression of previously treated conventional plasma cell myeloma. However, the anaplastic morphology can be encountered in newly diagnosed cases and might pose a major diagnostic challenge. Herein, we present a rare case of anaplastic plasma cell myeloma with $(14 ; 16)$ translocation which was diagnosed initially as a non-hematopoietic malignancies due to its unusual clinicopathological profile comprising acute presentation, extremely anaplastic morphology, and negative staining of CD38 immunohistochemical marker. In view of lack of clinical suspicion of plasma cell myeloma, no serological investigations for myeloma had been requested initially. In fact, high index of suspicion of myeloma arose only when results of MRI and CT scan came out revealing bony lytic lesions and collapsed vertebrae. Subsequently, bone marrow biopsy was repeated and revealed an extensive infiltration with sheets of neoplastic plasma cells which were strongly positive for CD138, KAPPA, and CD56 IHC markers.
\end{abstract}

Keywords Anaplastic myeloma $\cdot$ CD38 IHC markers $\cdot \mathrm{t}(14 ; 16)$

\section{Introduction}

Anaplastic cell myeloma is a rare and therapy-resistant subtype of plasma cell myeloma with poor prognosis. It usually manifests as an adverse progression of previously treated conventional plasma cell myeloma. However, the anaplastic morphology can be encountered in newly diagnosed cases and might pose a diagnostic challenge.

Herein, we present a rare case of anaplastic plasma cell myeloma with $(14 ; 16)$ translocation that was initially diagnosed as a non-hematopoietic malignancy due to unusual clinic-pathological profile comprised of acute presentation, extremely anaplastic morphology and for being negative for CD38 marker.

Mansour S. Aljabry

M.ALJABRY4210@GMAIL.com; MALJABRY@KSU.EDU.SA

1 Hematopathology, King Khalid University Hospital-King Saud University, P.O Box 2925, Riyadh 11461, Kingdom of Saudi Arabia

\section{Case report}

A 62-year-old female presented to the emergency department with fever, persistent headache, and easy bruising for 1 week duration. The patient also complained of progressive lower limb weakness and shortness of breath for the last 1 month. She was also suffering from diabetes mellitus and osteoarthritis. Her family history revealed that her older sister died of breast cancer 10 years ago. On physical examination; she was pale, had few large bruises on the left flank and her body temperature was $37.8{ }^{\circ} \mathrm{C}$. There was no hepatosplenomegaly or lymphadenopathy.

\section{Methods and materials}

The laboratory findings revealed a hemoglobin of $82 \mathrm{~g} / \mathrm{L}$ $(120-160 \mathrm{~g} / \mathrm{L})$, red blood cell (RBC) count was $3.15 \times 10^{12}$, L $\left(4.2-5.5 \times 10^{12} / \mathrm{L}\right)$, leukocyte count was $1.9 \times 10^{9} / \mathrm{L}(4.5$ $11 \times 10^{9} / \mathrm{L}$ ) with myelocytes $3 \%$, neutrophils $21 \%$, monocytes $9 \%$, and lymphocytes $67 \%$. Platelet count was $12 \times 10^{9} / \mathrm{L}$ 
$\left(140-450 \times 10^{9} / \mathrm{L}\right)$. Biochemical markers revealed high levels of LDH: $780 \mathrm{U} / \mathrm{L}(100-190 \mathrm{U} / \mathrm{L})$, uric acid: $509 \mu \mathrm{mol} / \mathrm{L}$ (155-357 $\mu \mathrm{mol} / \mathrm{L})$ and serum calcium level: $2.78 \mathrm{mmol} / \mathrm{L}$ (2-2.55 mmol/L) while serum albumin was $39 \mathrm{mg} / \mathrm{dL}(30$ $50 \mathrm{mg} / \mathrm{dL}$ ). Renal and liver function tests were within normal limits. Peripheral blood smear showed leukoerythroblastic blood picture with few large atypical cells (blast-looking cells) representing about $1 \%$. Severe thrombocytopenia was confirmed.

Patient was admitted with a provisional diagnosis of acute leukemia for further investigations. Bone marrow aspirate was a dry tap and showed only few erythroid and myeloid precursors without any abnormal cells. Touch imprint for bone marrow biopsy was cellular and showed large atypical cells with polymorphic nuclear pattern, inconspicuous nucleoli and abundant amount of cytoplasm. Some cells were multinucleated with deeply bluish and vacuolated cytoplasm (Fig. 1A). Flow cytometric immunophenotyping of both peripheral blood and bone marrow aspirate did not yield any conclusive results. Bone marrow biopsy was markedly hypercellular ( $100 \%$ cellularity) with diffuse infiltration by sheets of large polymorphic neoplastic cells which were completely replacing the normal hematopoiesis. The initial panel of immunohistochemistry (IHC) stains was negative for LCA (CD45), cytokeratin and CD38 markers. An extended panel of IHC was performed including CD3, CD4, CD5, CD8, CD10, CD20, CD30, CD34, CD61, CD79a, CD99, myeloperoxidase (MPO), terminal deoxynucleotidyl transferase (TDT), PAX-5, desmin, neuron-specific enolase (NSE), and S100 markers.
However, they were all found to be negative. The conclusion of bone marrow report was undifferentiated neoplasm in favor of non-hematopoietic malignancies for further work-up.

Abdominal and pelvic ultrasound examination revealed mild hepatosplenomegaly with no focal lesion was detected. Mutli-sequentail MRI for whole spine showed collapsed L5 vertebral body, anterior wedging of L1 and mild thickening of prevertebral soft tissue from D7 down to D10 (Fig. 1B). CT scan of chest, abdomen, and pelvis revealed presence of a lytic bone lesion involving L5 with compression fractures. No lymphadenopathy or organomegaly was noticed. The final impression of the radiology team was highly suggestive of plasma cell myeloma for further investigation.

A monoclonal band of IgG Kappa was detected using serum protein electrophoresis. The Kappa to Lambda ratio (K/L ratio) was $19.47(0.26-1.65)$ indicating very high level of Kappa light chain. Serum $\beta 2$ macroglobulin was $5.1 \mathrm{~g} / \mathrm{dL}$ (1-2.5 mg/L). Serological assays for human immunodeficiency virus (HIV), Epstein-Barr virus (EBV), and hepatitis B and $\mathrm{C}$ were negative.

A repeat bone marrow examination was performed for definite diagnosis. Bone marrow aspirate showed 10\% large atypical plasmacytoid cells with polymorphism, multinucleation, and immature morphology. Bone marrow biopsy was extensively infiltrated with sheets of neoplastic plasma cells that were strongly positive for CD138, KAPPA, and CD56 whereas CD5, CD10, CD20, CD38, CD79a, Lambda, BCL-6, and MUM were negative (Fig. 1C-F obtained from the second bone marrow).

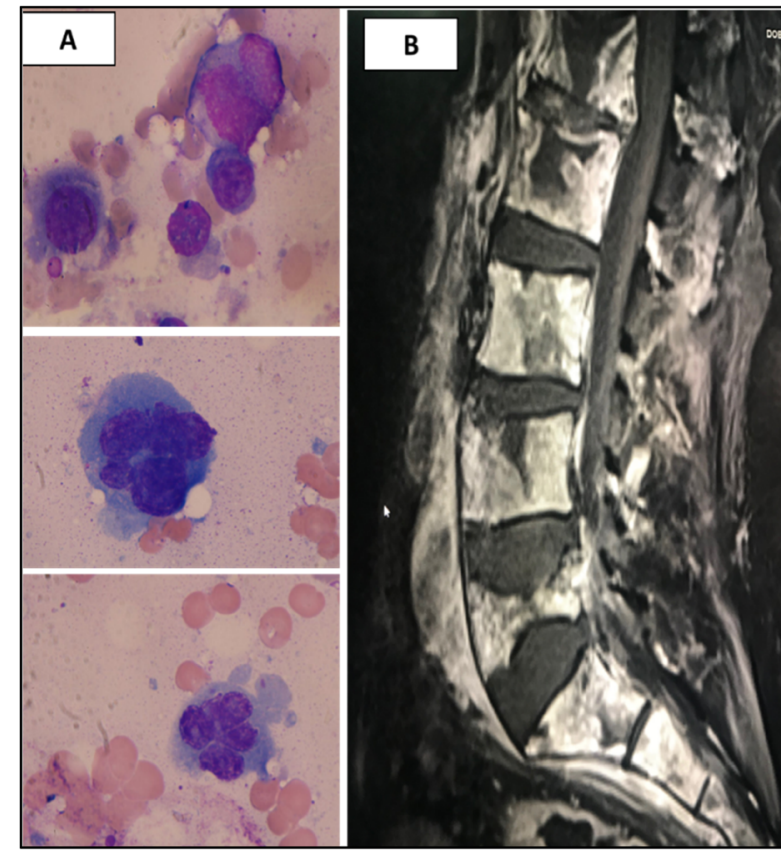

Fig. 1 Pathological and radiological features: A: Large atypical polymorphic plasma cells (megakaryocyte- like) in touch imprint of bone marrow biopsy. B: MRI of spine showed collapsed L5 vertebral body with anterior wedging of L1 vertebra. C: Diffuse infiltration of bone

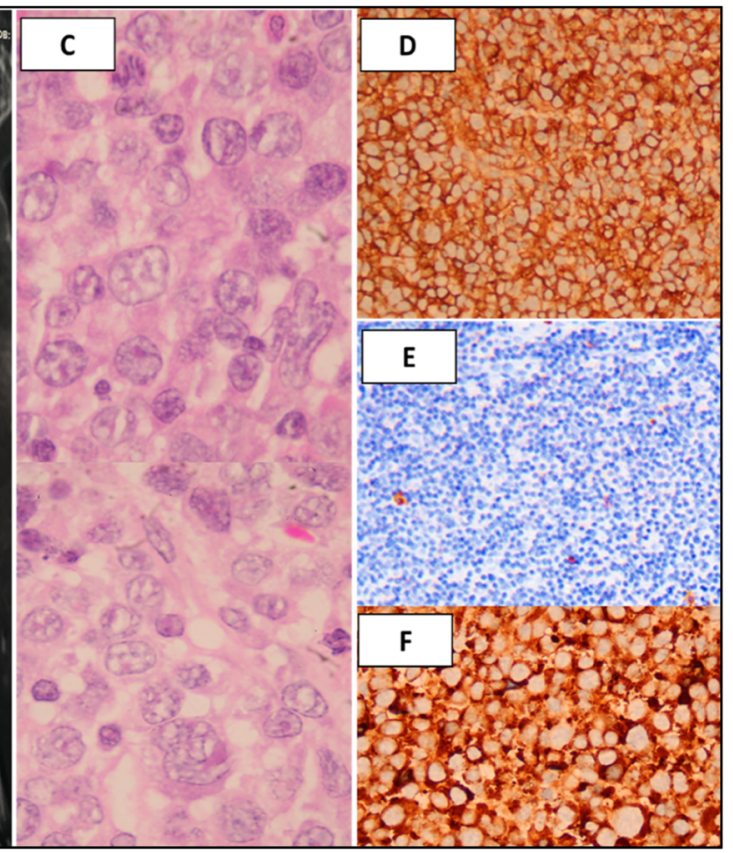

marrow biopsy with sheets of large polymorphic neoplastic cells [H\&E,100]. D and E: Plasma cells show strongly positivity for CD138 IHC marker (D), whereas CD38 is completely negative $(\mathbf{E})$. F: Kappa light chain revealed strong positivity in almost all plasma cells 
Flow cytometric immunophenotyping was performed on bone marrow biopsy but did not encounter enough plasma cells and hence, IHC stains for CD38, CD56, C138, Kappa, and Lambda were carried out on the first bone marrow biopsy and were consistent with the second bone marrow immunophenotyping. Cytogenetic analysis and FISH studies demonstrated a t(14;16) (q32;q23)-IGH/MAF translocation in $85 \%$ of the cells. The final diagnosis was released as CD38 negative anaplastic plasma cell myeloma.

The patient was admitted in the intensive care unit due to septicemia and severe thrombocytopenia. She was started on antibiotics and supportive therapy with pulses of dexamethasone. The plan was to treat her with bortezomibdexamethasone regimen followed by autologous stem cell transplantation once recovered from septicemia. Unfortunately she deteriorated and died with overwhelming pulmonary infection after 1 week.

\section{Discussion}

Anaplastic plasma cell myeloma is an aggressive morphological variant of myeloma that is usually associated with insidious onset, involvement of extramedullary sites and extremely poor prognosis [1-3]. It has been reported as initial presentation of plasma cell myeloma (PCM) or as adverse progression of previously treated conventional plasma cell myeloma [4]. The mean age at presentation is 53 years and the survival rate is usually less than 3.5 months [5]. Moreover, anaplastic PCM is associated with a high frequency of $17 \mathrm{p}(\mathrm{p} 53)$ deletions, 1q21(CKS1B) amplifications, and immunoglobulin A ( $\operatorname{IgA})$ isotype. [6] Lack of CD38 marker has rarely been reported in anaplastic plasma cell myeloma [7].

CD38 is a type II transmembrane glycoprotein involved mainly in intracellular calcium metabolism through hydrolysis of cyclic ADP-ribose and synthesis of NAADP. CD38 molecule is expressed as a surface marker on the hematopoietic stem cells and downregulates as the cells attain maturity [8]. However, plasma cells, whether normal or malignant, exhibit overexpression of CD38 marker, a feature exploited as a potential therapeutic target for daratumumab, the first anti-CD38 monoclonal antibody approved for treatment of plasma cell myelomas [9].

Loss of CD38 marker has been observed in some cases of refractory or relapsed plasma cells myelomas and after commencement of therapy with daratumumab. Bataille et al. found that four newly diagnosed cases out of 29 conventional plasma cell myelomas were negative for CD38 while in another study, only two cases out of 1000 patients, either at the time of diagnosis or during relapse, were found to be CD38 negative [10]. Association of anaplastic plasma cell myeloma with negative CD38 marker was reported previously in a single case report of newly diagnosed young patient. [7] This rare association poses a major diagnostic challenge that may delay the diagnosis and hence, the proper management.

The mechanism underlying the loss of CD38 molecules on the surface of myeloma cells remains obscure. Mikiko et al. reported spontaneous loss of CD38 phenotype in two relapsed plasma cell myeloma cases and postulated some genetic or epigenetic modifications occurring within CD38 epitopecoding regions [11]. However, no conclusive evidence can be drawn from such limited data.

On the other hand, level of expression of CD138 in plasma cell myeloma is variable among cells but the overall expression is usually higher and more consistent than CD38 marker. Interestingly, low level expression of CD138 was associated with more immature phenotype and poor response to lenalidomide [12].

According to Mayo Clinic stratification of myeloma and risk-adapted therapy, $\mathrm{t}(14 ; 16)$ is associated with high risk and poor prognosis [13]. However, the data about its clinical impact on prognosis of plasma cell myeloma is conflicting. On multivariate analysis of 32 myeloma patients, it was concluded that $\mathrm{t}(14 ; 16)$ is not prognostic. [14] While in the contrary, in some other studies, it was associated with worse clinical outcome [15]. The incidence of this genetic abnormality among plasma cell myeloma patients is very low representing only about 3.2\% [16]. Ammannagari et al. reported an anaplastic plasma cell myeloma patient with complex karyotype involving $13 q$ deletion, $\mathrm{t}(14 ; 16)$, and hyperdiploidy who died shortly after commencement of novel chemotherapy for myeloma. [2]

Moreover, the morphology was extremely anaplastic with markedly diffuse infiltration by poorly differentiated atypical cells which yielded a dry tap aspirate. Furthermore, negative staining of CD38 marker in the screening panel of IHC stains raised the possibility of undifferentiated carcinoma and made plasma cell myeloma less likely.

The diagnosis of the present case was delayed for 10 days in view of lack of clinical suspicion of plasma cell myeloma because of insidious onset of symptoms and thrombocytopenia which led to deviation of the clinical suspicion more toward acute leukemia or aggressive lymphoma or carcinoma. Subsequently, no serological investigation for myeloma had been requested initially. In fact, high index of suspicion of myeloma arose only when results of MRI and CT scan came out revealing bony lytic lesions and collapsed vertebrae. This observation highlights the importance of incorporation of advanced radiological techniques in resolving such challenging cases.

In this context, the most complex issue in the differential diagnosis was exclusion of plasmablastic lymphoma (PBL) as it may present with cytomorphological features that are nearly identical to anaplastic plasma myeloma. [17] However, the presence of lytic bone lesions and serum monoclonal protein along with absence of both EBV and HIV infections are in favor of anaplastic plasma cell myeloma rather than PBL. 
Moreover, PBL is highly associated with translocations, gains, and deletions of MYC gene. Genetic profile of 36 PBL cases has demonstrated that $57 \%$ and $50 \%$ of PBL cases were found to have genetic alterations in MYC gene and somatic mutation in PRDM1 gene, respectively [18]. To the best of our knowledge, $t(14 ; 16)$ has not been reported in PBL.

\section{Conclusion}

The diagnosis of anaplastic plasma cell myeloma can be a dilemma without high index of clinical suspicion as cell morphology might be quite peculiar and polymorphic. Moreover, integration of advanced radiological techniques along with full panel immunophenotying, including both CD38 and CD138 markers, is the gold standard diagnostic approach for such highly aggressive neoplasms.

\section{Compliance with ethical standards}

Conflict of interest The authors declare that they have no conflict of interest.

\section{References}

1. Zervas K, Constantinou N, Karakantza M, Tsigalidou-Balla V (1995) Anaplastic myeloma. Leuk Lymphoma 16(5-6):515-518

2. Ammannagari N, Celotto K, Neppalli V, Lee K, Holstein SA (2016) Anaplastic multiple myeloma: an aggressive variant with a poor response to novel therapies. Clin Lymphoma Myeloma Leuk 16(9):e129-ee31

3. Foucar K, Raber M, Foucar E, Barlogie B, Sandler CM, Alexanian R (1983) Anaplastic myeloma with massive extramedullary involvement. Report of two cases. Cancer 51(1):166-174

4. Fujimi A, Nagamachi Y, Yamauchi N, Kanisawa Y (2017) Morphological transformation of myeloma cells into multilobated plasma cell nuclei within 7 days in a case of secondary plasma cell leukemia that finally transformed as anaplastic myeloma. Case Rep Hematol 2017:5758368

5. Allen SL, Coleman M (1990) Aggressive phase multiple myeloma: a terminal anaplastic transformation resembling high-grade lymphoma. Cancer Investig 8(3-4):417-424

6. Shaughnessy J (2005) Amplification and overexpression of CKS1B at chromosome band 1q21 is associated with reduced levels of p27Kip1 and an aggressive clinical course in multiple myeloma. Hematology 10(Suppl 1):117-126
7. Singh N, Agrawal N, Mehta A, Panaych A, Sekhri R (2018) CD38negative myeloma with anaplastic morphology at presentation: a case report. Indian J Hematol Blood Transfus 34(2):362-364

8. Fedele G, Di Girolamo M, Recine U, Palazzo R, Urbani F, Horenstein AL et al (2013) CD38 ligation in peripheral blood mononuclear cells of myeloma patients induces release of protumorigenic IL-6 and impaired secretion of IFNgamma cytokines and proliferation. Mediat Inflamm 2013:564687

9. Raedler LA (2016) Darzalex (daratumumab): first anti-CD38 monoclonal antibody approved for patients with relapsed multiple myeloma. Am Health Drug Benefits 9(Spec Feature):70-73

10. Bataille R, Jego G, Robillard N, Barille-Nion S, Harousseau JL, Moreau P et al (2006) The phenotype of normal, reactive and malignant plasma cells. Identification of "many and multiple myelomas" and of new targets for myeloma therapy. Haematologica 91(9):1234-1240

11. Ise M, Matsubayashi K, Tsujimura H, Kumagai K (2016) Loss of CD38 expression in relapsed refractory multiple myeloma. Clin Lymphoma Myeloma Leuk 16(5):e59-e64

12. Kawano Y, Fujiwara S, Wada N, Izaki M, Yuki H, Okuno Y et al (2012) Multiple myeloma cells expressing low levels of CD138 have an immature phenotype and reduced sensitivity to lenalidomide. Int J Oncol 41(3):876-884

13. Dingli D, Ailawadhi S, Bergsagel PL, Buadi FK, Dispenzieri A, Fonseca R, Gertz MA, Gonsalves WI, Hayman SR, Kapoor P, Kourelis T, Kumar SK, Kyle RA, Lacy MQ, Leung N, Lin Y, Lust JA, Mikhael JR, Reeder CB, Roy V, Russell SJ, Sher T, Stewart AK, Warsame R, Zeldenrust SR, Rajkumar SV, Chanan Khan AA (2017) Therapy for relapsed multiple myeloma: guidelines from the Mayo stratification for myeloma and risk-adapted therapy. Mayo Clin Proc 92(4):578-598

14. Avet-Loiseau H, Malard F, Campion L, Magrangeas F, Sebban C, Lioure B, Decaux O, Lamy T, Legros L, Fuzibet JG, Michallet M, Corront B, Lenain P, Hulin C, Mathiot C, Attal M, Facon T, Harousseau JL, Minvielle S, Moreau P, for the Intergroupe Francophone du Myelome (2011) Translocation t(14;16) and multiple myeloma: is it really an independent prognostic factor? Blood 117(6):2009-2011

15. Nair B, van Rhee F, Shaughnessy JD Jr, Anaissie E, Szymonifka J, Hoering A et al (2010) Superior results of total therapy 3 (2003-33) in gene expression profiling-defined low-risk multiple myeloma confirmed in subsequent trial 2006-66 with VRD maintenance. Blood 115(21):4168-4173

16. Vega F, Chang C-C, Medeiros LJ, Udden MM, Cho-Vega JH, Lau C-C, et al (2005) Plasmablastic lymphomas and plasmablastic plasma cell myelomas have nearly identical immunophenotypic profiles. 806-15 $\mathrm{p}$

17. Elyamany G, Al Mussaed E, Alzahrani AM (2015) Plasmablastic lymphoma: a review of current knowledge and future directions. Adv Hematol 2015:315289

18. Montes-Moreno S, Martinez-Magunacelaya N, Zecchini-Barrese T, Villambrosia SG, Linares E, Ranchal T et al (2017) Plasmablastic lymphoma phenotype is determined by genetic alterations in MYC and PRDM1. Mod Pathol 30(1):85-94 